\title{
The Potential of the m-Health Platform to Safeguard Public Health: The Nigerian Example
}

\author{
Allen Nnanwuba Adum \\ Department of Mass Communication, \\ Nnamdi Azikiwe University, Awka, Anambra State, Nigeria \\ Ogochukwu Ekwenchi \\ Department of Mass Communication, \\ Nnamdi Azikiwe University, Awka, Anambra State, Nigeria \\ Ojinime Ebelechukwu Ojiakor \\ Department of Mass Communication, \\ Nnamdi Azikiwe University, Awka, Anambra State, Nigeria \\ Gloria Nwakego Chukwuemeka \\ Department of Mass Communication, \\ Nnamdi Azikiwe University, Awka, Anambra State, Nigeria
}

\begin{abstract}
Nigeria has a problem with fake drugs. This issue got to an intolerable height in 1989 when over 150 children died as a result of ingesting paracetamol syrup containing diethylene glycol. The National Agency for Food and Drug Administration and Control (NAFDAC) was formed in 1993, as an agency under the Nigerian federal ministry of health, to check the tide of fake drugs and adulterated products. To achieve this mission, NAFDAC, in 2010, launched the Mobile Authentication Service (MAS) - a mobile-phone m-Health platform, which empowers medication drug users to instantaneously verify the authenticity or otherwise of a medication drug before purchase. This study sought to ascertain the workability of MAS among medication drug users; and factors negating this platform. The study was designed as a survey. Data was collected from 400 medication drug users in Lagos state, Nigeria, through a structured survey. Results show that 91 percent of the respondents were aware of MAS and 53 percent among these utilized it prior to purchasing medication drugs, while 9 percent were neither aware of MAS nor utilize it. The notable barriers to the use of MAS found in this study were lack of awareness and the unreliable nature of the MAS.
\end{abstract}

Keywords: Mobile Authentication Service, Public Health Informatics, Fake drugs, m-Health.

DOI: $10.7176 / \mathrm{NMMC} / 79-07$

Publication date: April $30^{\text {th }} 2019$

\section{Introduction}

Mobile telephony, popularly known as GSM, was introduced in Nigeria in the year 2001. Prior to this development, Nigerians relied on telephone landlines provided by state-owned telecom service, NITEL (Nigerian Telecommunications). Today, with the advent of mobile telephony, 118,850,928 Nigerians have been connected to GSM lines. Out of this number, 553,425 actively use their mobile phones (WWW.ncc.gov.ng). This was not obtainable in the era of landline phone services in Nigeria.

Mobile telephony has engendered many possibilities. Nigerians have been empowered to make and receive calls from any part of the country, once there is network coverage by any of the operational telecom services. Also, SMS could be sent and received in a matter of minutes or even seconds. Nigerians no longer need to go and stand in queues at NITEL call centres or phone booths to make calls; neither do they need to write letters which might take days, weeks or even months to get to their various destinations. The Internet can now be accessed on the go by owners of mobile phones. This situation brings to mind the reality of Marshall McLuhan's idea of a Global Village. 
In recent times, the use of mobile telephony has gone beyond the conventional calls and SMS. Today, mobile phones are being used as m-Health tools. Mobile Health, also known as mHealth or m-Health implies the use of mobile communication devices such as mobile phones for health services (Cipresso et al, 2012). One good example of m-Health is the Mobile Authentication Service (MAS) introduced by Nigeria's National Agency for Food and Drug Administration and Control (NAFDAC) in the year 2010. According to Osuolale (2011:3) "this is a world-first, showing the pro-active [stance] of Nigeria in the global fight to rid the world of fake medication."

Nigeria is the largest medication drugs market in Africa. The issue of fake pharmaceuticals has been a problem in. Nigeria. Nigeria imports 70 percent of its drugs from India and China, two main sources of fake and adulterated pharmaceutical products. Also, The World Health Organization reports that, 70 percent of drugs in circulation in Nigeria are counterfeit (WHO Report 2014). Again, Osibo (1998) observes that there may be more fake drugs than authentic drugs in circulation in Nigeria. Akuyili (2005) notes that drug counterfeiting started in Nigeria way back in the 60 s; meaning, Nigerians have been dying from fake drugs for decades. “

According to Davison (2011) and Bansal, Malla, Gudala and, Tiwari (2013), a counterfeit medication or a counterfeit drug is regarded as a medication or pharmaceutical product which is produced and sold with the intent to deceptively represent its origin, authenticity or effectiveness.

In 1988, the World Health Assembly passed a resolution requesting every member-nation to help combat the menace of counterfeit drugs. Barely a year after this resolution, the issue of deaths from fake drugs in Nigeria became unbearable with the deaths of 150 children as a result of ingesting paracetamol syrup which contained diethylene glycol.

The World Customs Organization estimates that the fake drug market is a \$200 Billion a year industry; with a strong base in developing economies. Also, the World Health Organization estimates that 30 percent of drugs in developing economies are faked and may be very harmful to consumers.

In order to check fake and adulterated drugs in Nigeria, the government established the NAFDAC in 1993; and in 1994 it became a full agency under the federal ministry of health.

In pursuit of its mandate, NAFDAC, on the 2nd of February 2010, launched the first Mobile Authentication Service (MAS) on anti- malaria drug, Lonart-DS, marketed by Greenlife Pharmaceuticals, Nigeria. MAS is a technology-based anti-drug counterfeiting mobile telephony initiative, developed by Sproxil Incorporated. Sproxil is a privately-owned company founded in 2008 (and incorporated in 2009) by Ghanaian-born Ashifi Gogo, a Holekamp Family Ph.D. Innovation Fellow at Dartmouth College. Sproxil provides a consumer SMS and App. product verification service which help consumers avoid purchasing counterfeit products. Sproxil has operations in Ghana (serving West Africa), Nigeria, Kenya (serving East Africa), and India (Sproxil Solutions, 2014).

NAFDAC's Mobile Authentication Service, powered by Sproxil, allows prospective Nigerian drug consumers to confirm the authenticity or otherwise of a particular drug at the point of purchase. The technical components of MAS include a scratch panel pre-printed by Sproxil that can be affixed on packs of medication or printed codes embossed directly by manufacturers on medication packs; mobile phone and GSM network service host the Sproxil authentication portal. All the consumer needs to do is to scratch the panel on the drug pack and text a 12digit number on it to 38353 without paying any charges. A confirmatory message as to the authenticity of the drug should come in a matter of seconds. 


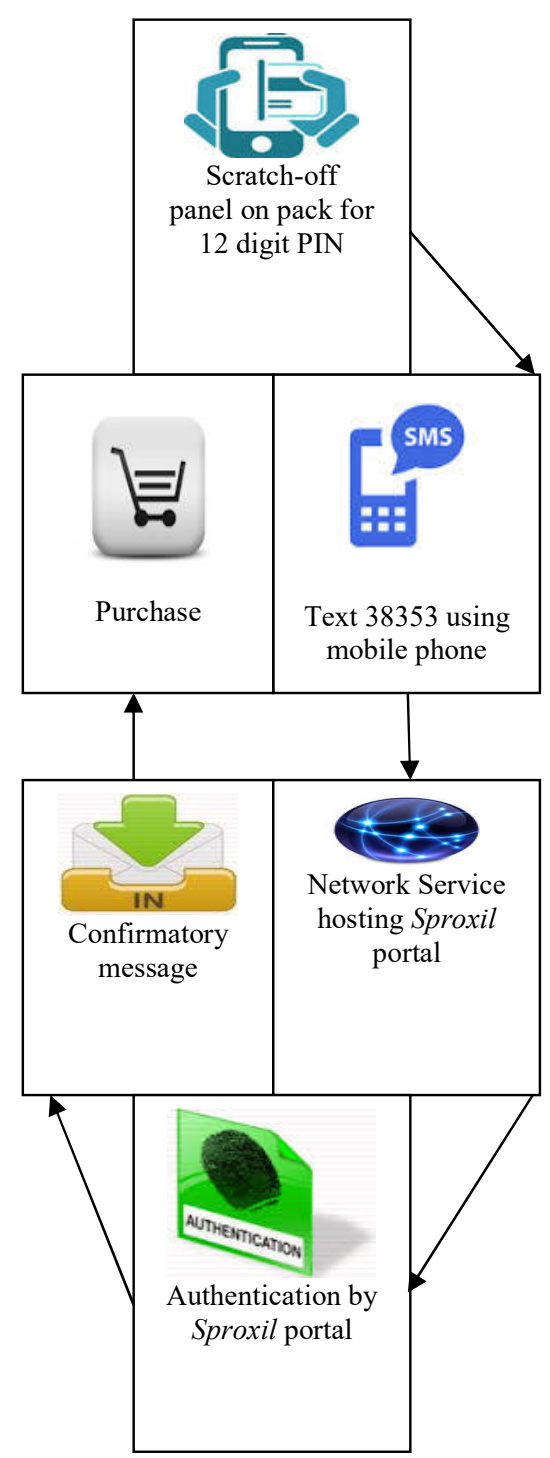

Figure 1. How MAS works.

But the question is: is this as seamless as it sounds? The lead author of this paper got a Lonart anti-malarial drug on the $21^{\text {st }}$ of January 2014, and sent the pin (182032090421) to 38353 by 07:22 pm. Up until now he's yet to get the confirmatory message from 38353. How many Nigerians face this kind of situation? Does it make them unwillingly to utilize MAS or perceive the service as unworkable? How many are indeed aware of the existence of MAS?

These questions are pertinent because, negligible utilization of m-Health tool such as MAS, as a result of certain barriers would amount to a big waste of public informatics which would have otherwise enhanced public health.

\section{Aims of study}

The main aim of the study was to investigate the utilization of NAFDAC's Mobile Authentication Service (MAS) among Nigerian medication drug users and barriers to utilizing this innovation. The study sought answers to the following questions:

1. Who among Nigerian medication drug users are aware of NAFDAC's Mobile Authentication

Service? 
2. How many of these medication drug users indeed utilize NAFDAC's Mobile Authentication Service?

3. What are the barriers to the utilization of the Mobile Authentication Service?

\section{Method}

This study was designed as a survey. Focus was on Lagos State, Nigeria. Lagos is a cosmopolitan city. This city is also a major seaport and with a population (according to Nigeria's 2006 population census) of 17.5 million (a population that is larger than the population of Rwanda, 11.46 million according to CIA World Fact book), it is the most populous city in Nigeria This strategic position of Lagos makes it a good starting point for almost every innovation in Nigeria. This had informed situating this study in Lagos State, Nigeria.

A sample of 400 medication drug users was used for the study. This sample was arrived at using Taro Yamane's formula for determining sample size $\mathrm{n}=\mathrm{N} / 1+\mathrm{N}(\mathrm{e})^{2}$. By a simple random sample we selected 10 Local Government Areas from the available 21 LGAs, using table of random digits, The Local Government Areas are: Ojo; Amuwo- odofin; Badagry; Alimosho; Ifako-ijaiye; Ikeja; Surulere; Mushin; Ikorodu and Apapa. A validated questionnaire was used as research instrument. Four hundred copies of the questionnaire were distributed at the rate of 40 copies per local government area; 389 completed surveys were returned, representing a response rate of 97 percent.

A series of questions were asked on awareness of NAFDAC's Mobile Authentication Service; utilization of Mobile Authentication Service and barriers to the utilization of Mobile Authentication Service.

\section{Theoretical basis}

This study was anchored on The Health belief Model (HBM). The HBM is a psychological model first developed in the 1950s by social psychologists Hochbaum, Rosenstock and Kegels. HBM is used to explain and predict health behaviors. In the light of this, the core assumptions of this study, in line with the HBM framework, are that a medication drug user will take a health-related action (i.e., use Mobile Authentication Service) if they:

- feel that a negative health condition (ailments as a result of ingesting fake drugs) can be avoided,

- have positive expectations that by taking a recommended action, he/she will avoid a negative health condition (i.e., using Mobile Authentication Service will be effective in helping them not to purchase fake drugs), and

- believe that they can successfully take a recommended health action (i.e., they can use Mobile Authentication Service without difficulties) (Rosenstock, 1974).

\section{Results}

The distribution in the sample was 37 percent male and 63 percent female. One third of the medication drug users are civil servants, one quarter professionals, one sixth business people, one eighth university students, one twentieth artisans and self-employed persons, one fortieth farmers and one sixtieth unemployed persons. The majority of these medication drug users were within the 18-30 age bracket. Data also show that 52 percent of the respondents were single, 47 percent married. The remaining one percent were either separated or divorced.

In terms of educational qualification, about two thirds of the respondents indicated that they have had secondary education; about 17 percent had first degrees or above while the remaining one fifth did not indicate any chosen option for the question.

We can therefore say that our respondents are young persons who fall mainly within the middle and lower classes of the Nigerian society.

\subsection{Purchase of Medication Drugs over the Counter}

Here we attempted to establish who among the respondents engaged in over the counter drug purchase. Survey question five in the questionnaire was used for this purpose. 


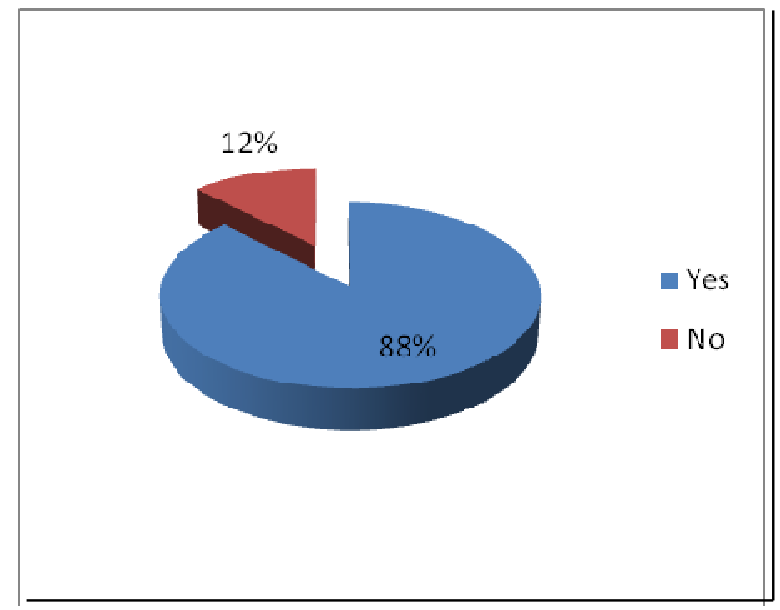

Figure 2. Respondents who purchased drugs over the counter.

The study found that over two thirds of the respondents purchased medication drugs over the counter, while 12 percent were affirmative that they did not purchase medication drugs over the counter. It appears logical to say that our data suggest that a majority among the respondents at one point in time have purchased medication drugs over the counter.

\subsection{Sources of drug supply}

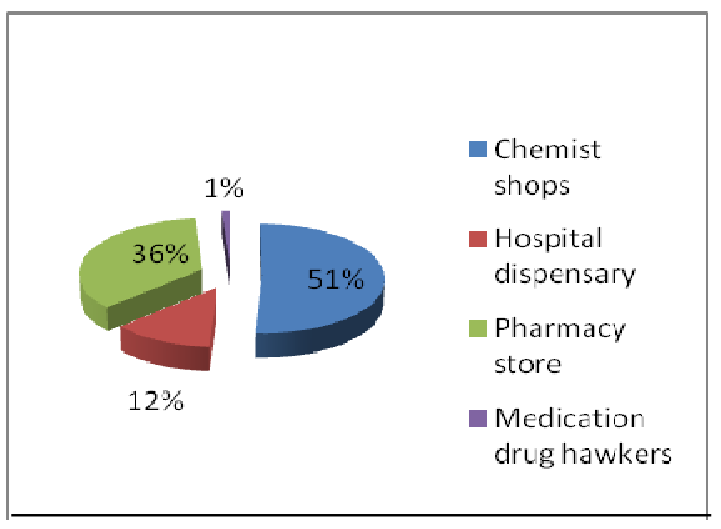

Figure 3. Respondents' main source of drug supply

Our data suggest that more of the respondents had Chemist shops as their main source of drug supply; 'Chemist' as they are popularly known in Nigeria are drug stores closer and more accessible to the ordinary citizenry. Figure 3 shows that 51 percent of the respondents purchased medication drugs from Chemist shops; a little above two fourths got drugs from pharmacy stores while 12 percent got drugs at hospital dispensaries. One percent of the respondents said they got drugs from hawkers. The 'Chemist' or 'Patent medicine store', by virtue of being run by people who might not be regarded as well trained medical personnel - even though most are governmentregistered - could become fertile grounds for the sale of fake drugs to unsuspecting members of the Nigerian public. That large number of people patronise the 'Chemist', as data in this study show, points to the need to utilize the MAS at the grassroots. 


\subsection{Ownership and use of mobile phones}

Table 1. Ownership and use of mobile phones

\begin{tabular}{|c|c|c|c|}
\hline & $\begin{array}{l}\begin{array}{l}\text { Own } \\
\text { mobile } \\
\text { phones }\end{array} \\
\text { 89) }(\mathrm{N}=3 \\
(\%)\end{array}$ & $\begin{array}{l}\text { Own mobile phones with text message features } \\
(\mathrm{N}=389) \\
(\%)\end{array}$ & $\begin{array}{l}\text { Respondents who } \\
\text { wrote } \\
\text { messages } \\
\qquad(\mathrm{N}=389) \\
(\%)\end{array}$ \\
\hline Yes & 97 & 100 & 93 \\
\hline No & 3 & 0 & 7 \\
\hline Total & 100 & 100 & 100 \\
\hline
\end{tabular}

Our data show that 97 percent of the respondents own mobile phones; virtually all these mobile phones have features for text messaging. This is against three percent that do not own mobile phones and seven percent that own mobile phones but cannot write text messages. Ninety-three percent of the respondents claimed they could write text messages.

Technology is something that appears to take time before people get accustomed to it. Having the right literacy means the ability to use ICT devices like the text messaging feature on mobile phones. Not having the necessary literacy apparently accounts for the inability of seven percent among the respondents to use mobile telephony text messaging feature.

\subsection{Awareness of the Existence of NAFDAC's Mobile Authentication Service}

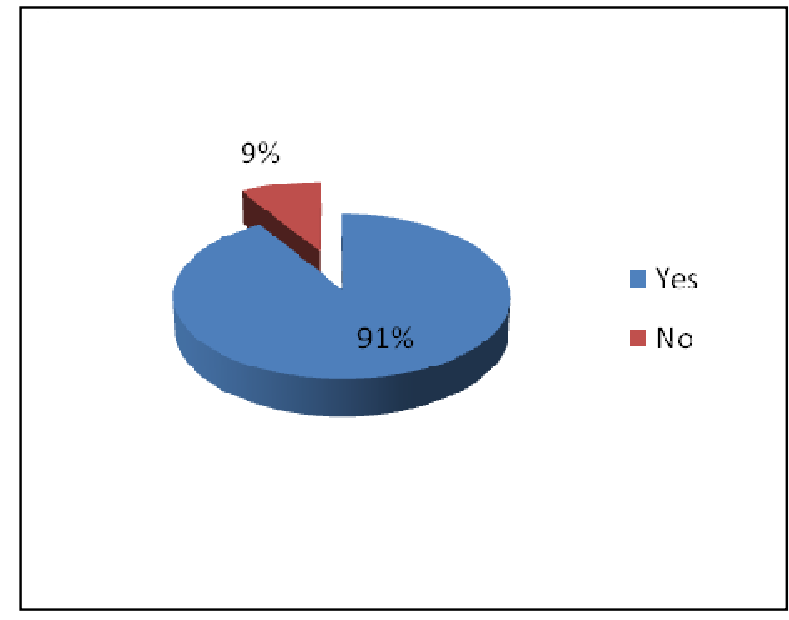

Figure 4. Respondents who have heard about NAFDAC'S MAS.

The data in Figure 4 show that as at the time of this study, majority of medication drug users studied in the Lagos area were aware of the existence of NAFDAC's Mobile Authentication Service. Only 9 percent of the respondents affirmed not knowing about the existence of MAS. This data would suggest that NAFDAC's public enlightenment campaigns have been largely successful in sensitizing the public on the need to safeguard their health through the utilization of MAS; but more still needs to be done by way of enlightenment to consolidate the gains already made. 


\subsection{Sources of information about NAFDAC's MAS}

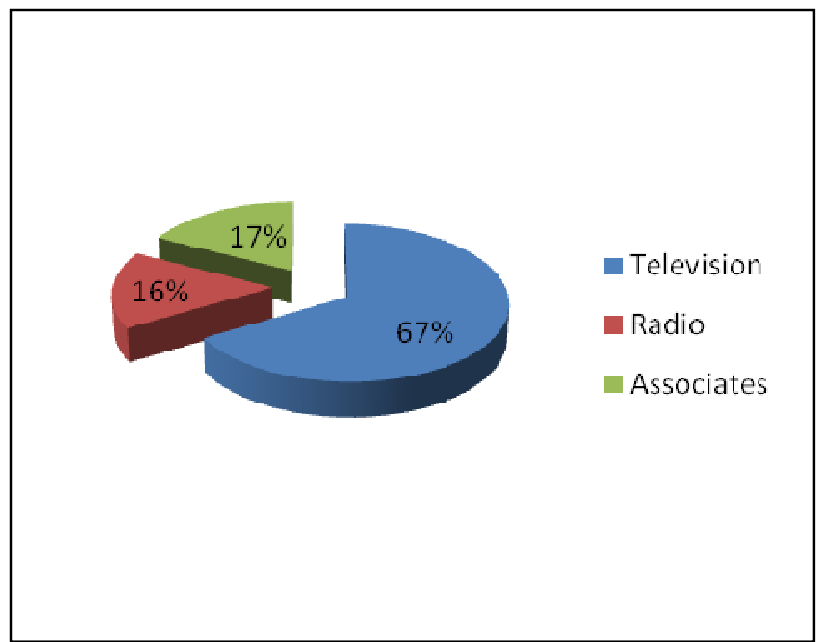

Figure 5. Respondents' sources of information about NAFDAC's MAS.

On the question of sources of information on NAFDAC's MAS, the study found that 67 percent of the respondents indicated that they got to know about the NAFDAC's MAS through enlightenment campaigns on television (Figure 5); Seventeen percent of the respondents said they got to know about MAS through associates, while 16 percent of the respondents said they got to know about MAS via the Radio. None of the respondents chose the Magazine, Newspapers, Billboards or Posters as the medium through which they got to know about MAS; therefore they were not reflected in our presentation.

\subsection{Utilization of NAFDAC's MAS}

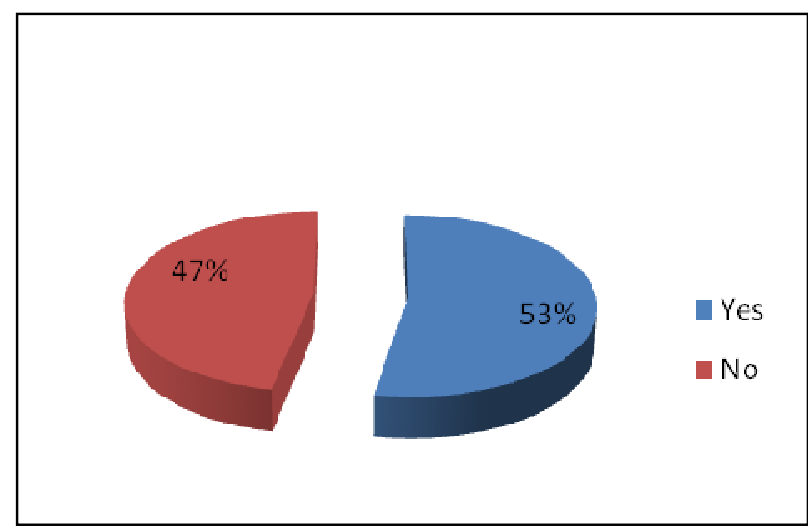

Figure 6. Respondents who have used MAS to confirm the authenticity of Medication drugs before purchase. 
With regard to the respondents' utilization of NAFDAC's MAS to authenticate medication drugs before purchase, we found that a little above two fourths of the respondents who said they were aware of MAS also said they have used it to confirm the authenticity of medication drugs before purchase; while over two fifths among these respondents were not affirmative as to having used MAS to authenticate medication drugs before purchase.

\subsection{Barriers to utilizing NAFDAC's MAS}

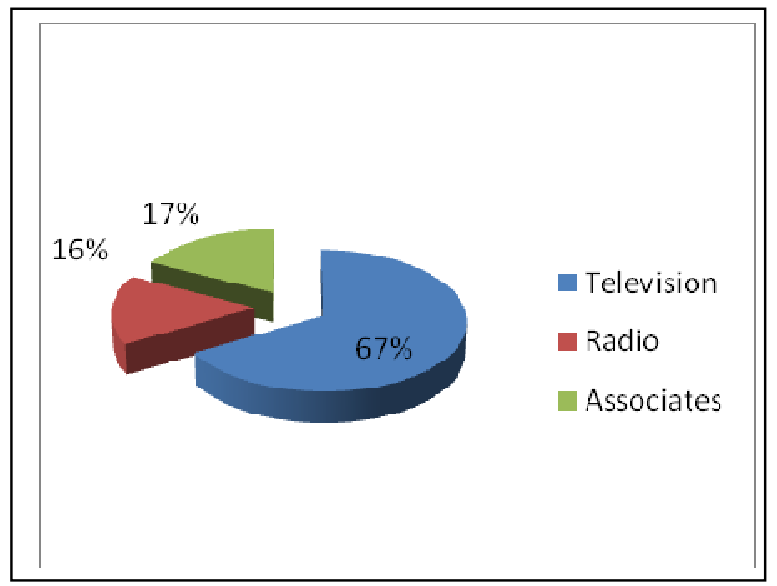

Figure 7. Respondents who have difficulties using MAS to confirm the authenticity of Medication drugs before purchase.

Data in Figure 7 show that close to 40 per cent of the respondents who used NAFDAC's MAS had some difficulties; notably, delayed or non-arrival of confirmatory SMS messages indicating whether a drug about to be purchased is genuine or not; while 61 percent said they had no problems using the mobile service. Network coverage is one issue that negates the operations of the authentication portal in relaying confirmatory message to medication drug users. Overall, the picture here is that MAS, going by the number of people who could use it without difficulties, as suggested by the findings of this study, has the potential to be a workable m-Health platform to safeguard the medication drug users from purchasing and ingesting fake drugs.

\subsection{Workability of NAFDAC's MAS}

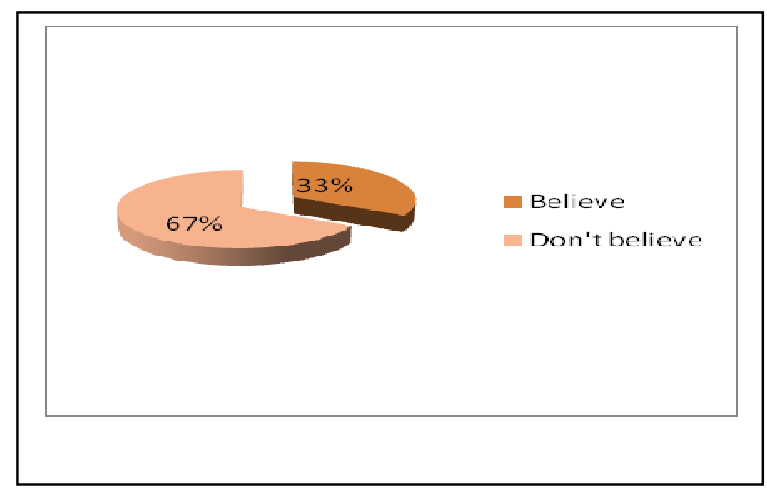

Figure 8. Respondents' perception of the workability of NAFDAC's MAS.

Part of this study examined how the respondents perceived the workability of NAFDAC's MAS. The data in Figure 8 reveals that 33.percent of the respondents believe that NAFDAC's MAS is workable in Nigeria, while 67 percent believe otherwise. The fact that the service is balky might be the basis for the position of those who do not believe in the workability of this m-Health platform. 


\section{Summary and Conclusion}

Our data show that our respondents are mainly young persons who come from the middle and lower classes of the Nigerian society.

The study found that more of the respondents are aware of NAFDAC's Mobile Authentication Service and a greater percentage among them use the mobile service before making purchase decisions. The data suggest that nearly all medication drug users studied, whose phones have text messaging features, can actually compose text messages. Our data also indicate that not all medication drug users who own mobile phones, and were aware of MAS, utilized the Mobile Authentication Service to verify the genuineness or otherwise of pharmaceutical products.

On the workability of the MAS m-Health platform, a sizeable number of the respondents who used the MAS, encountered difficulties ranging from delayed confirmatory messages to non-arrival of confirmatory messages. However, a significant number of MAS users expressed high hopes of its workability in Nigeria.

Overall, the findings of the study suggest that the potential to safeguard public health through the NAFDAC's MAS m-Health platform is feasible and with little effort at technical reappraisal and improvement, the MAS innovation could be a critical element that could assist Nigeria in the fight against fake drugs which are harmful to medication drug users.

\section{Recommendations}

Based on the findings of this study, it becomes imperative to make recommendations that could help NAFDAC, as well as relevant stakeholders who may find the contents of this research helpful. These recommendations are as follows:

- NAFDAC should as a matter of necessity, intensify efforts on massive integrated awareness creation on its Mobile Authentication. Service. This is because, the relative success or failure of an initiative, irrespective of how noble, is measured by the level of awareness and acceptability by its targets. Statistics gotten in the course of this study suggest high level of awareness, but more needs to be done to further consolidate this gain.

- NAFDAC should also bear in mind that not everyone who owns mobile phones that are text messagingenabled, can write text messages. This is another pitfall to the Mobile Authentication Service, because even when medication drugs users are willing to utilize MAS, they may be deterred by the inability to compose text messages. Special considerations should be given to this category of persons in the event of any future modification of MAS.

- Issues of delayed or non arrival of confirmatory messages from the Mobile Authentication Service portal should be addressed. This appears to be the greatest stumbling block to the utilization of the service. First time users of MAS who fail to get confirmatory text messages from the portal, could be discouraged from using it further, and may also discourage others with their experiences. Positive testaments from the users of MAS could go a long way in influencing and convincing other medication drugs users, who are yet to utilize MAS.

- Seminars and workshops should be organised periodically at different locations, to sensitize and create adequate awareness about MAS. Community and village heads as well as popular celebrities should also be integrated in campaigns pertaining to MAS. The goodwill and positive images of these individuals could be transferred to MAS, thus making it acceptable to medication drugs users.

\section{References}

Akunyili, D. (2005). “Counterfeit and Sub-standard Drugs, Nigeria's Experience: Implications, Challenges, Actions and Recommendations". A paper presented at a meeting for key interest groups on health organised by the World Bank in Washington D. C. 10th -11th March 2005.

Bansal, D, Malla S, Gudala K, Tiwari P (March 2013). “Anti-Counterfeit Technologies: A Pharmaceutical Industry Perspective", Sci Pharm 81 (1) 1-13.

\section{CIA World Factbook}

Cipresso, P.; Serino S., Villani D., Repetto C., Selitti L., Albani G., Mauro A., Gaggioli A., Riva G. (2012). "Is your phone so smart to affect your states? An exploratory study based on psychophysiological measures". Neurocomputing 84: 23-30.

Davison, M. (2011). "Pharmaceutical Anti-Counterfeiting:Combating the Real Danger from Fake Drugs', Wiley. p426. 
Osibo, O.O. 1998. Faking and counterfeiting of drugs. West African Journal of Pharmacy. 12(1):53 - 57.

Osuolale, J. A. (2011). "The Use of Mobile Phone to check for the Authenticity of Pharmaceutical Products in Nigeria a case study of Mobile Authentication Service (MAS)". Department of Archaeology and Anthropology University of Ibadan, Nigeria.

Rosenstock, I. (1974). Historical Origins of the Health Belief Model. Health Education Monographs. Vol. 2 No. 4.

Sproxil Solutions (2014). Sproxil and IBM partner to fight counterfeit drugs. Retrieved 30th March 2014 from http://www.en.wikipedia.org/wiki/sproxil

WHO Report 2014, [Online] Available:

http://www.who.int/medicines/services/counterfeit/impact/ImpactF S/en/index1.html (July 12, 2014)

www.ncc.gov.ng 